\title{
The Causes of Conversion from Laparoscopy to Laparotomy in Patients with Laparoscopic Repair of Perforated Peptic Ulcer
}

\author{
Chien-Hua Lin',2*, Der-Ao Chou1 ${ }^{1}$, Yueh-Tsung Lee ${ }^{1}$, Hurng-Sheng Wu ${ }^{1}$ \\ ${ }^{1}$ Department of Surgery, Chang-Bing Show Chwan Memorial Hospital, Changhua, Chinese Taipei \\ ${ }^{2}$ IRCAD, Changhua, Chinese Taipei \\ Email:
}

Received 30 December 2014; accepted 12 February 2015; published 15 February 2015

Copyright (C 2015 by authors and Scientific Research Publishing Inc.

This work is licensed under the Creative Commons Attribution International License (CC BY). http://creativecommons.org/licenses/by/4.0/

(c) (i) Open Access

\begin{abstract}
Purpose: Perforated peptic ulcer is an emergency condition. Laparoscopic ulcer repair is a feasible and safe procedure. The aim of this study was to research the efficacy of laparoscopic repair of peptic ulcer and to discuss the causes of conversion from laparoscopy to laparotomy. Methods: We collected 34 patients with perforated peptic ulcer underwent laparoscopic surgery from October 2003 to October 2008. Thirty four patients with perforated peptic ulcer underwent laparoscopic intervention and 6 cases were converted to laparotomy. The demographics, laboratory data, perioperative data, morbidity and mortality were compared. Results: In demographics of two groups, there were no significant differences in sex, age, location, and mean duration of symptoms of acute abdominal pain. However, there were significant differences in median size of perforation, mean duration of history of peptic ulcer related pain, and the experiences of surgeon. There were no significant differences in the laboratory data and perioperative data of two groups. In morbidity and mortality of two groups, there were no significant differences in leakage, wound infection, intraabdominal abscess, ileus, urinary tract infection, pneumonia, and mortality, but there was significant difference in overall morbidity in two groups. Conclusions: Laparoscopic repair of perforated peptic ulcer is safe and could be used in routine clinical practice. However, patients with larger perforations $(>10 \mathrm{~mm})$, longer duration of history peptic ulcer related pain ( $>2$ years), and learning curve of surgeon could be associated with conversion rate. It is associated with higher morbidity in patients with conversion from laparoscopy to laparotomy.
\end{abstract}

\section{Keywords}

Laparoscopy, Perforated Peptic Ulcer, Repair, Conversion Rate

\footnotetext{
${ }^{*}$ Corresponding author.
}

How to cite this paper: Lin, C.-H., Chou, D.-A., Lee, Y.-T. and Wu, H.-S. (2015) The Causes of Conversion from Laparoscopy to Laparotomy in Patients with Laparoscopic Repair of Perforated Peptic Ulcer. Surgical Science, 6, 75-79. 


\section{Introduction}

Perforated peptic ulcer (PPU) is a common emergency and a major cause of death in elderly patients. It is usually treated by surgery, including laparotomy with simple closure or a definitive acid-reduction procedure, laparoscopic, or nonoperative treatment [1]-[3]. As we know that peptic ulcer is associated with Helicobacter pylori (Hp), simple closure followed by Helicobacter pylori eradication has become the most used procedure in perforated ulcer treatment [4]. Simple closure of PPU could be achieved by laparotomy and laparoscopy. Laparoscopic repair of PPU has been applied since 1990 [1]. Several studies have been reported that laparoscopic offers improved patient outcome with significantly less morbidity [5]. However, few studies have been reported to discuss the causes of conversion from laparoscopy to laparotomy. Herein, we reported our experience of laparoscopic repair of PPU about conversion from laparoscopy to laparotomy.

\section{Patients and Methods}

From October 2003 to October 2008, 164 patients with PPU and underwent surgical intervention at ShowChwan Memorial Hospital were reviewed retrospectively.

34 patients underwent laparoscopic surgery, and 6 patients were converted to laparotomy. 130 patients underwent laparotomy initially were excluded, including septic shock (87 cases), serious associated cardiopulmonary diseases (23 cases), previous abdominal operations (12 cases), and gastric outlet obstruction (8 cases).

The 34 patients with PPU underwent laparoscopic surgery were divided into two groups: non-conversion group (28 cases) and conversion group (6 cases).

Five surgeons were involved these operations, including one surgeon with experience of no more 10 laparoscopic repair of PPU and four surgeons with experience of more than 10 cases of laparoscopic repair of PPU.

Patients underwent general anesthesia with muscle relaxation at operating room. Postoperative patients were routinely received treatment of nasogastric tube (NG) insertion, proton pump inhibitors and placement of abdominal drains. Abdominal drains were removed when the ascites were clear and no more amount of $50 \mathrm{ml}$ per day.

NG was removed when the bowel sound recovered and no more amount of $200 \mathrm{ml}$ per day. Patients presented with abdominal distension, absence of passage of flatus, nausea, abdominal pain or abdominal plain film showed bowel distension was defined as ileus.

\section{Statistical Analysis}

Student's t test was used for statistical analysis. $P \leq 0.05$ was accepted as statistically significant.

\section{Results}

The characteristics of the patients: (Table 1 )

There were 20 male and 14 female patients were enrolled. 28 patients were non-conversion group, 6 patients were conversion group. The mean age of non-conversion group was 56.2 years old; conversion group was 58.1 years old. The locations of perforation were duodenal $(19 / 34 ; 16$ in non-conversion group, 3 in conversion group), juxtapyloric (15/34; 12 in non-conversion group, 3 in conversion group), and stomach (1/34, one in nonconversion group). The median size of perforation was $5.5 \mathrm{~mm}(2-10)$ in non-conversion group, and $13.5 \mathrm{~mm}$ (5 - 30) in conversion group. There was significant difference between two groups. The mean duration of acute abdominal pain was 15.3 hours (4 - 24) in non-conversion group, and 21.5 hours (10 - 28) in conversion group. There was no significant difference between two groups. However, there was significant difference between two groups in mean duration of history of peptic ulcer related pain (non-conversion group: 6.3 months; conversion group: 23.5 months).

There were five surgeons included in studies, including one surgeon with the experience of no more than ten laparoscopic repair of PPU, and the other four surgeons with the experience of more than ten laparoscopic repair of PPU. There were significant differences between the two groups in the experience of surgeon.

The laboratory data of the patients: (Table 2)

The patient's hemotocrit (HCT) in non-conversion group is 35.5; and conversion group is 33.3 (\%). The white blood cell (WBC) count in non-conversion group is 12,538 (/ul); and conversion group is 14,760 (/ul). The segment form of WBC is 84 (\%) in non-conversion group; and 82.6 (\%) in conversion group. The C-reactive protein 
Table 1. The characteristics of two groups.

\begin{tabular}{lcc}
\hline & Non-conversion & Conversion \\
\hline No. & 28 & 6 \\
M:F & $16: 12$ & $4: 2$ \\
Mean age & $56.2(25-92)$ & $58.1(32-83)$ \\
Location: & 16 & 3 \\
$\quad$-Duodenal & 12 & 3 \\
$\quad$-Juxtapyloric & 1 & 0 \\
$\quad$-Stomach & $5.5(2-10)$ & $13.5(5-30)^{*}$ \\
Median size of perforation (mm) & $15.3(4-24)$ & $21.5(10-28)$ \\
Mean duration of acute onset (Hour) & $6.3(0.1-12)$ & $23.5(0.5-48)^{*}$ \\
$\begin{array}{l}\text { Mean duration of history of peptic ulcer related pain } \\
\text { (chronic upper abwdominal pain) (months) }\end{array}$ & & \\
Experiences of Surgeon: & $4 / 28$ & $4 / 6^{*}$ \\
$-<10$ & $24 / 28$ & $2 / 28$ \\
$->10$ & & \\
\hline${ }^{*} P<0.05$. & & \\
\end{tabular}

Table 2. The laboratory data of two groups.

\begin{tabular}{ccc}
\hline & Non-conversion & Conversion \\
No. & 28 & 6 \\
Hct (\%) & $35.5(28.2-46.3)$ & $33.3(30.2-42.6)$ \\
WBC (/ul) & $12538(8900-25800)$ & $14760(9200-26900)$ \\
-segment (\%) & $84(62-94)$ & $82.6(77-94)$ \\
CRP $(\mathrm{mg} / \mathrm{dl})$ & $2.6(0.2-14.5)$ & $4.7(1.2-16.4)$
\end{tabular}

${ }^{*} P<0.05$. Hct: hemotocrit, WBC: white blood cell, CRP: C-reactive protein.

(CRP) of non-conversion group is $2.6(\mathrm{mg} / \mathrm{dl})$; and the conversion group is $4.7(\mathrm{mg} / \mathrm{dl})$. There were no significant difference between two groups in laboratory data, including HCT, WBC, segment form of WBC, and CRP.

The perioperative data of the patients: (Table 3 )

The operative time in non-conversion group is 68.7 ( $\mathrm{min})$; and the conversion group is 72.3 (min). The retention of abdominal drains in non-conversion group is 4.2 (days); and the conversion group is 5.6 (days). The time to normal diet in non-conversion group is 4.5 (days); and the conversion group is 6.2 (days). The time to oral analgesia in non-conversion group is 3.4 (days); and the conversion group is 4.1 (days). The time to full mobilization in non-conversion group is 2.3 (days); and the conversion group is 3.8 (days). The hospital stay in nonconversion group is 6.8 (days); and the conversion group is 7.6 (days)

There were no significant differences between the two groups in perioperative data, including operative time, the retention of abdominal drains, the time to normal diet, the time to oral analgesia, the time to full mobilization, and the hospital stay.

The morbidity and mortality of the patients: (Table 4)

As Table 4 shows, there were no significant differences between the two groups in leakage, wound infection, intraabdominal abscess, ileus, urinary tract infection, pneumonia, mortality. However the overall morbidity of conversion group is significant higher than that of non-conversion group.

\section{Discussion}

Owing to the advances in the medical treatment of peptic ulcer disease, the number of elective ulcer surgeries 
Table 3. The perioperative data of two groups.

\begin{tabular}{ccc}
\hline No. & Non-conversion & Conversion \\
\hline Operative time (min) & 28 & 6 \\
Retention of abdominal drain (days) & $68.7(42-152)$ & $72.3(56-168)$ \\
Time to normal diet (days) & $4.2(2.5-10.5)$ & $5.6(4.5-14.2)$ \\
Time to oral analgesia (days) & $4.5(3.2-13.0)$ & $6.2(5.1-14.2)$ \\
Time to full mobilization (days) & $3.4(2-8.5)$ & $4.1(3.2-10.5)$ \\
Hospital stay (days) & $2.3(1.8-4.5)$ & $3.8(2.8-8.4)$ \\
\hline
\end{tabular}

${ }^{*} \mathrm{P}<0.05$.

Table 4. The morbidity and mortality of two groups.

\begin{tabular}{ccc}
\hline & Non-conversion & Conversion \\
No. & 28 & 6 \\
Leakage & 1 & 1 \\
Wound infection & 4 & 2 \\
Intraabdominal abscess & 1 & 1 \\
Ileus & 2 & 1 \\
UTI & 1 & 0 \\
Pneumonia & 1 & 1 \\
Overall morbidity & $5 / 28$ & $4 / 6^{*}$ \\
Mortality & 1 & 1 \\
\hline
\end{tabular}

${ }^{*} P<0.05$ UTI: urinary tract infection.

decreased. However, the number of patients requiring surgical intervention for complications such as perforations remains relatively unchanged [1] [2] [6]-[9]. However, simple closure followed by Helicobacter pylori eradication has become the most used procedure in perforated ulcer treatment [4]. Laparoscopic repair for PPU could be routinely used and different techniques has been tried. It could provide decrease postoperative wound pain and encourages early mobilization and return to normal daily activities. The benefit of early discharge and early return to work may outweigh the consumable cost incurred in the execution of laparoscopic procedures. However, there is $13 \%-21.5 \%$ rate of conversion [1] [10]. The causes of conversion include perforated nonpyloric gastric ulcers, unidentifiable perforations, perforations larger than $10 \mathrm{~mm}$, and bleeding during suturing [1]. In our study, the causes of conversion may include size of perforation, mean duration of history of peptic ulcer related pain, and the experience of surgeons.

As Siu WT, et al. [1] reported, the majority of the ulcer perforations were small. Perforations more than 10 mm may be associated with rate of conversion. In our study, the conversion group has larger median size of perforation than non-conversion group, and the median size of perforation in conversion group is over $10 \mathrm{~mm}$. It means that larger size of perforation would increase the rate of conversion, especially the size is over $10 \mathrm{~mm}$.

Besides, in our study, patients with longer history of peptic ulcer or peptic ulcer related pain may increase the possibility of conversion, especially for patients with history of peptic ulcer for more than two years.

There were five surgeons involved in this study, only one surgeon has experience of no more ten cases of laparoscopic repair of PPU. The other four surgeons have experience of more than ten cases of laparoscopic repair of PPU. It means that learning curve may be associated with the rate of conversion.

Besides, we found the rate of leakage, wound infection, intra-abdominal abscess, ileus, urinary tract infection, and pneumonia were not increased in patients with conversion from laparoscopy to laparotomy. However, that 
the overall morbidity would increase once the patients underwent conversion from laparoscopy to laparotomy, but it will not increase the rate of mortality.

\section{Conclusion}

We think that laparoscopic repair of PPU is a safe alternative treatment. However, several conditions were associated with rate of conversion, including larger perforations $(>10 \mathrm{~mm})$, longer duration of history peptic ulcer related pain ( $>2$ years), and learning curve of surgeon. Once conversion from laparoscopy to laparotomy, it will increase the overall morbidity.

\section{References}

[1] Siu, W.T., Leong, H.T., Law, B.B., et al. (2002) Laparoscopic Repair for Perforated Peptic Ulcer. A Randomized Controlled Trial. Annals of Surgery, 235, 313-319. http://dx.doi.org/10.1097/00000658-200203000-00001

[2] Koo, J., Ngan, Y.K. and Lam, S.K. (1983) Trends in Hospital Admissions, Perforation and Mortality of Peptic Ulcer in Hong Kong from 1970 to 1980. Gastroenterology, 84, 1558-1562.

[3] Alagaratnam, T.T. and Wong, J. (1998) No Decrease in Duodenal Ulcer Surgery after Cimetidine in Hong Kong. Journal of Clinical Gastroenterology, 10, 25-27. http://dx.doi.org/10.1097/00004836-198802000-00007

[4] Rodríguez-Sanjuán, J.C., Fernández-Santiago, R., García, R.A., et al. (2005) Perforated Peptic Ulcer Treated by Simple Closure and Helicobacter Pylori Eradication. World Journal of Surgery, 29, 849-852. http://dx.doi.org/10.1007/s00268-005-7797-x

[5] Bhogal, R.H., Athwal, R., Durkin, D., et al. (2008) Comparison between Open and Laparoscopic Repair of Perforated Peptic Ulcer Disease. World Journal of Surgery, 32, 2371-2374. http://dx.doi.org/10.1007/s00268-008-9707-5

[6] Gunshefski, L., Flancbaum, L., Brolin, R.E., et al. (1990) Changing Patterns in Perforated Peptic Ulcer Disease. The American Surgeon, 56, 270-274.

[7] Cocks, J.R. (1992) Perforated Peptic Ulcer: The Changing Scene. Digestive Diseases, 10, 10-16. http://dx.doi.org/10.1159/000171339

[8] Walt, R., Katschinski, B., Logan, R., et al. (1986) Rising Frequency of Ulcer Perforation in the United Kingdom. The Lancet, 3, 489. http://dx.doi.org/10.1016/S0140-6736(86)92940-5

[9] Kulber, D.A., Hartunian, S., Schiller, D., et al. (1990) The Current Spectrum of Peptic Ulcer Disease in the Older Age Groups. The American Surgeon, 56, 737-741.

[10] Siu, W.T., Chau, C.H., Law, B.B., et al. (2004) Routine Use of Laparoscopic Repair for Perforated Peptic Ulcer. British Journal of Surgery, 91, 481-484. http://dx.doi.org/10.1002/bjs.4452 
Scientific Research Publishing (SCIRP) is one of the largest Open Access journal publishers. It is currently publishing more than 200 open access, online, peer-reviewed journals covering a wide range of academic disciplines. SCIRP serves the worldwide academic communities and contributes to the progress and application of science with its publication.

Other selected journals from SCIRP are listed as below. Submit your manuscript to us via either submit@scirp.org or Online Submission Portal.
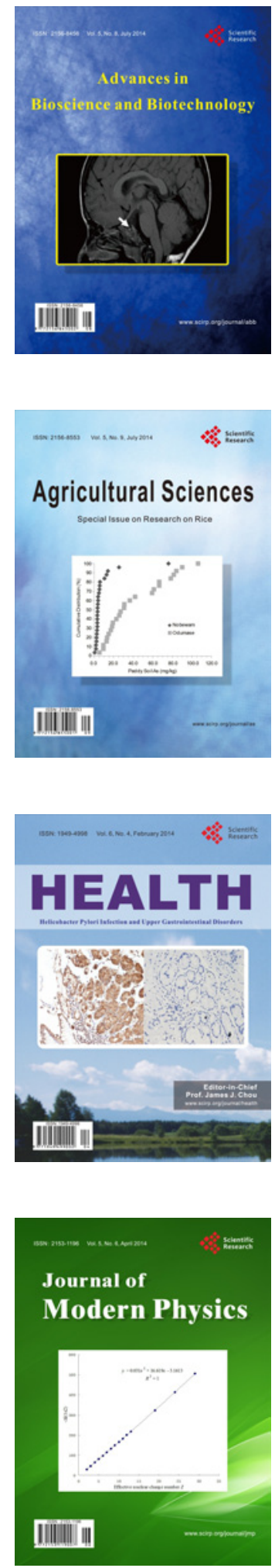
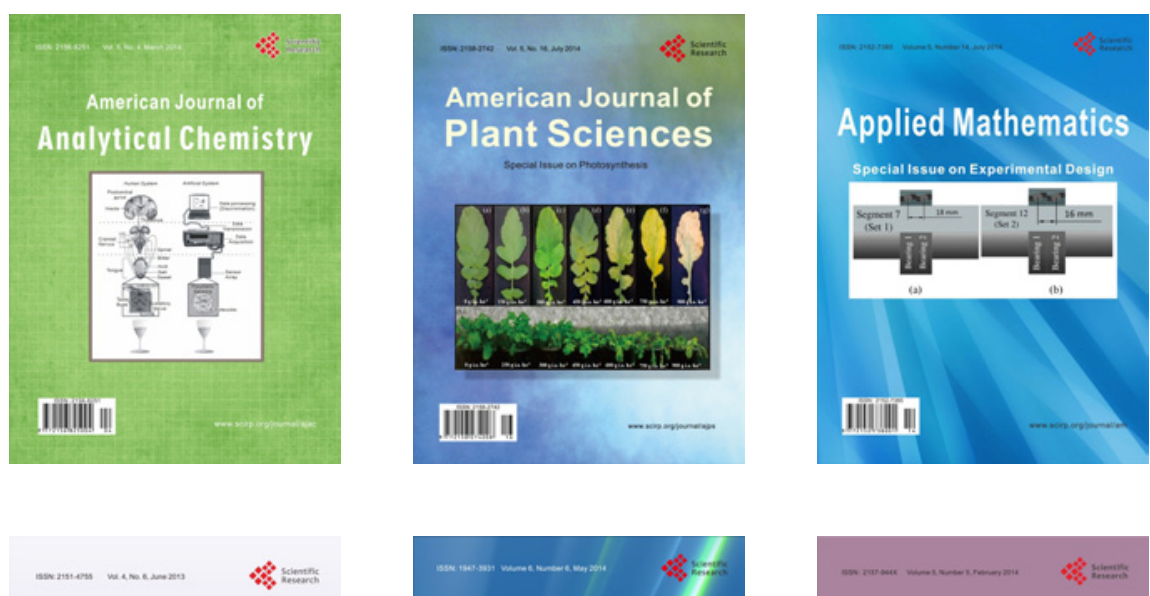

Creative Education
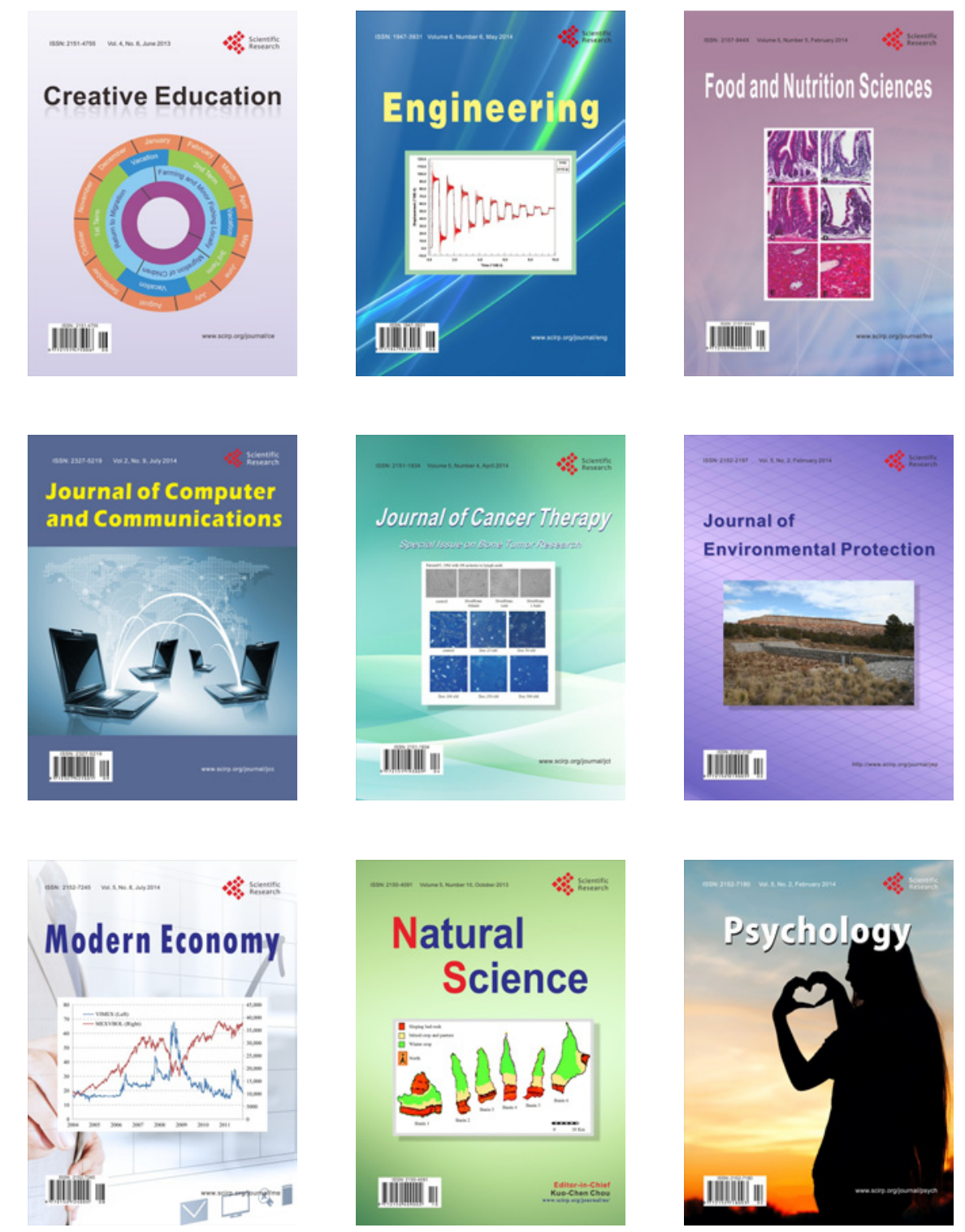